\title{
Optimization of Economic Load Dispatch for 2.5 MW Solar Power System
}

\author{
Hifsa Shahid ${ }^{1}$, Zaeem Aslam ${ }^{1 *}$, Zeeshan Mahmood ${ }^{1}$ \\ ${ }^{1}$ University of Engineering \& Technology, Lahore, PAKISTAN \\ *Corresponding Author: zaeem.aslam1@gmail.com \\ Citation: Shahid, H., Aslam, Z. and Mahmood, Z. (2018). Optimization of Economic Load Dispatch for \\ 2.5 MW Solar Power System. European Journal of Sustainable Development Research, 2(3), 27. \\ https://doi.org/10.20897/ejosdr/85934
}

Published: July 9, 2018

\begin{abstract}
Economic load dispatch (ELD) is a complicated issue, when renewable energy sources are also considered with thermal power generation systems. It becomes challenging and difficult to find the optimum solution at lower fuel costs, in order for generated power to meet the active power load demand. This paper primarily focuses on the modeling of ELD for solar power plants synchronized with Thermal power plants. In this paper, the purposed optimization method used is Genetic algorithm (GA). According to which, all thermal generators in the system will supply output power at lowest fuel rate however satisfying the system limitations. Minimum fuel cost of a generator will be calculated by using generator characteristic curve for all generators present in the system. With the help of GA, achievable range for best solution is attained while restricting the output power of thermal generators. Proposed system priority to achieve is solar at first and generators on second such that generator or combination of generators resulting in lowest cost will be on second priority. Simulations on various test systems were performed including one with six thermal generators and the other with six thermal generators and solar power system. By using MATLAB the proposed problem is simulated.
\end{abstract}

Keywords: solar power, thermal power generation, economic load dispatch, genetic algorithm

\section{INTRODUCTION}

Due to Increase demand in electricity resulting from rapid growth, development and progress worldwide the electricity shortfall is increasing day by day. The main objective has now shifted to improve the efficiency and performance of the existing system along with to lower the cost of solution at the same time increasing the reliability of the power system. New conventional and non-conventional sources of electricity generation are now being installed in order to meet the ever increasing demands of electricity consumption.

As a result of rapid changes in the modern world, electricity shortfall is a major issue as in the modern day; economy of a country is entirely dependent on the energy consumption. As the existing conventional sources of energy are diminishing with time, search of wind, solar, biomass and other renewable energy sources is becoming more attractive for energy experts. For the proper working of a power system in order to ensure its reliability, electricity generation must be equal to the load demand. Hence, it is necessary to look for an optimum solution for thermal generators power output at their minimal cost of operation with minimum consumption of Diesel fuel, economic load dispatch technique is used. Solar being the cheapest source of energy with minimum operating cost is kept at first priority but due to its less efficiency (less - area to use full electricity conversion ratio) it requires a lot of free space thus limiting the overall size of the solar system. Further, the entire dependency on Sun, solar power system cannot be used as single primary source as the output of solar power system is highly variable which create a need for another secondary power source available at all the time. 
All over the globe numerous studies and research works have been carried out to resolve economic load dispatch difficulties of the power systems (Shilaja and Ravi, 2017). Many different algorithms have been proposed addressing issues and problems related to economic load dispatch of stand-alone thermal power generation plant and their losses (Liu, 2010). The fuel curve of thermal generators and the use of quadratic, nonlinear and linear curves for the assessment of fuel cost of the thermal units has also been explained in this paper.

The basic purpose of this paper is to find economic load dispatch of the thermal power plants along with the synchronization of renewable energy source such as solar to the national grid which increase the overall complexity of the system (Khan et al., 2015).

Probabilistic distribution function from Gram-charier theory is used to solve the transmission line flows and for the analysis of the power system (Liu, 2010). In order to solve the solar power energy problem probabilistic optimal power flow is used (Safie, 1989).

There are many different methodologies associated with power generation systems to solve the economic load dispatch problems. Two foremost methodologies are to use optimization technique and mathematical programming approach. In previous research works done on economic load dispatch problems most commonly used techniques include Newton Rapshon Method, Gradient Method, Lambda Iteration, Interior Point Method, Perturb and Observation and penalty function method (Phonrattanasak et al., 2013). These methods are applicable only when the thermal power generators have linear and monotonically increasing fuel cost curves. Whereas, for thermal generation units, fuel cost curve is usually nonlinear. In which case Heuristic optimization methods need to be used to solve multifaceted ELD problems.

An ELD problem comprising of thermal power generation units and solar power plant is considered in this paper. Since solar plant yield is entirely dependent on Solar Irradiance which is varying in nature and is different at different intervals of a day, as a result output from solar power plant is considered as a constraint in proposed economic load dispatch problem. Output from Solar power plant is taken at three different intervals of a day which include morning, evening and mid-day when solar power output is at its peak. By using genetic algorithm technique, a heuristic optimization method is used to find the best solution for the mentioned problem while satisfying all the system limitations. The results obtained by running MATLAB simulations clearly prove the usefulness of genetic algorithm while resolving the problems associated to economic load dispatch when renewable energy sources are combined with thermal generation units.

\section{ECONOMIC LOAD DISPATCH}

Due to massive increase in demand of electricity, energy crisis has reached to its maximum degree in all over the world in previous ten years. In today's world the most difficult and important part in the interconnection of large generators in parallel in order to run the load economically and to full fill the load demands is planning and optimized working of generating units. For this reason optimized and timely switching of generating units is made possible to ensure maximum cost savings without affecting the load.

A thermal power generating unit mainly comprises of three major parts a boiler, a steam turbine and a generator. The first part of an energy conversion unit is a boiler in which fuel is supplied. This fuel can be in the form of diesel, gas, furnace oil, coal etc. Fuel is used to heat water present in the boiler to change it into super-heated vapor state. The amount of heat produced by the fuel depends upon the calorific value of the fuel used. These vapors go in to the steam chamber. Turbine is rotated with the help of vapors produced in the boiler. Steam turbine is further connected to a generator through a shaft (Gaing, 2013). Rotation of shaft result in the electrical output of generator which is then received and then transmitted through electrical wires to the load where power is needed.

Normally, multiple numbers of generating units are connected and synchronized in parallel in order to ensure the proper working of large amount of load connected to the system. Schematic diagram of $\mathrm{N}$ number of generators connected in parallel is shown in the Figure 1. These generators are connected to each other through a common copper bas bar. The primary objective of multiple generating units is to make sure safe and reliable working of the power system while keeping the operating and fuel cost of generating units to the minimum level possible.

If the input output characteristic curve of all the connected generators is same and identical to each other than load can be symmetrically divided on all the generators connected in parallel. However, in most cases this is not the case. All or most of the generators connected are of different brands, having variable efficiency and dissimilar input output characteristics. All these generators will also have different fuel cost curves at different power outputs as shown in Figure 2. It increases the need of ELD to vary the power of generating units within the desired generating limits of each individual generator to meet output power demand within optimal fuel cost (Safie, 1989). 


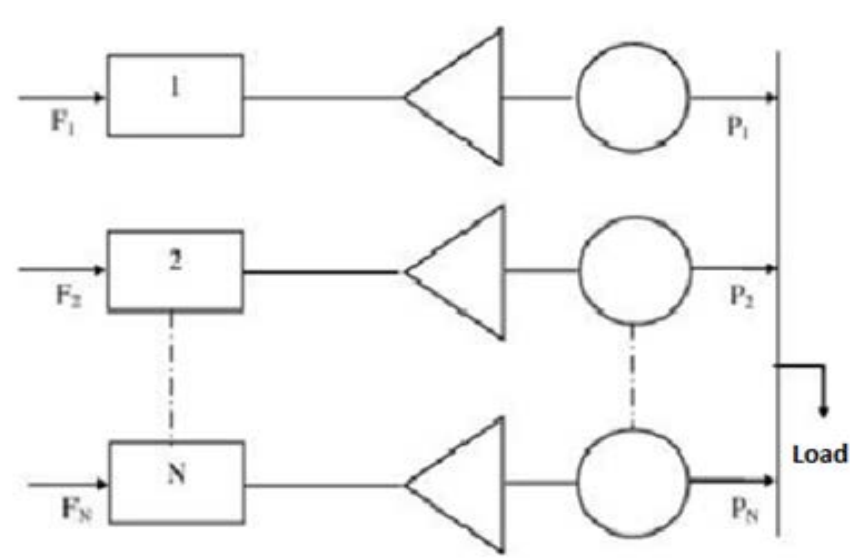

Buss Bar

Figure 1. Schematic diagram of parallel generator

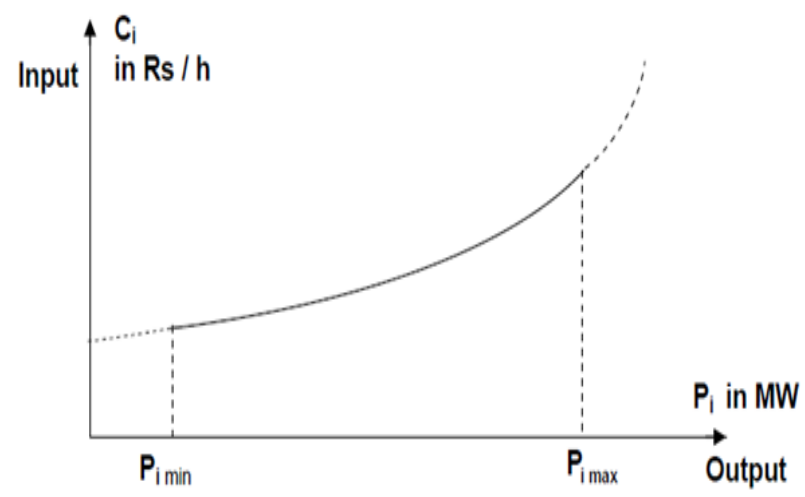

Figure 2. Thermal generator Operating Cost

\section{GENETIC ALGORITHM}

Genetic Algorithm founded by john Holland is used widely in many applications of engineering and related fields. The objective is to investigate \& develop the mechanism, which can be introduced into the world of computers.

GA gives us an idea of the fittest solution present in a given population ( $\mathrm{Yu}$ and Rosehart, 2012; Bakirtzis et al., 1994). It helps us to decide the best possible solution available out of number of options. With the help of GA chromosomes can be modeled as strings of $1 \mathrm{~s}$ and 0 s while clearly demonstrating how populations of these chromosomes can be evolved by implementing different techniques of mutation, selection and crossover which are found in natural sciences. This approach of GA starts from estimation of a given set of input variables and congregates to the best closest solution in a form of an inverted triangle. In next step a new population or a set of variables are created and the finest possible solution is formed base on the fitness level. In this way the best possible optimal solution from a given set of population in accordance to the environment for which they are best suited is chose.

\section{Selection}

The first step of genetic algorithm is to choose a best solution out of a given population for the purpose of reproduction. The best variable/solution is selected which will have highest probability to be selected in the next round for reproduction. Best variable/solution is referring to an individual's ability in a certain environment. Members of population or different variables of a population compete each other on the basis of their qualities. The individual having best performance is selected for the next step. In this manner all the bad solutions are eliminated at the end of the process while keeping the population size fixed at every stage.

\section{Crossover}

The most significant element in Genetic algorithm is crossover of species. Crossover function produces a new variable or an offspring by substitution of one or more bits of two parents. Combination of chromosomes takes place to form new specie. This process is called as recombination. 


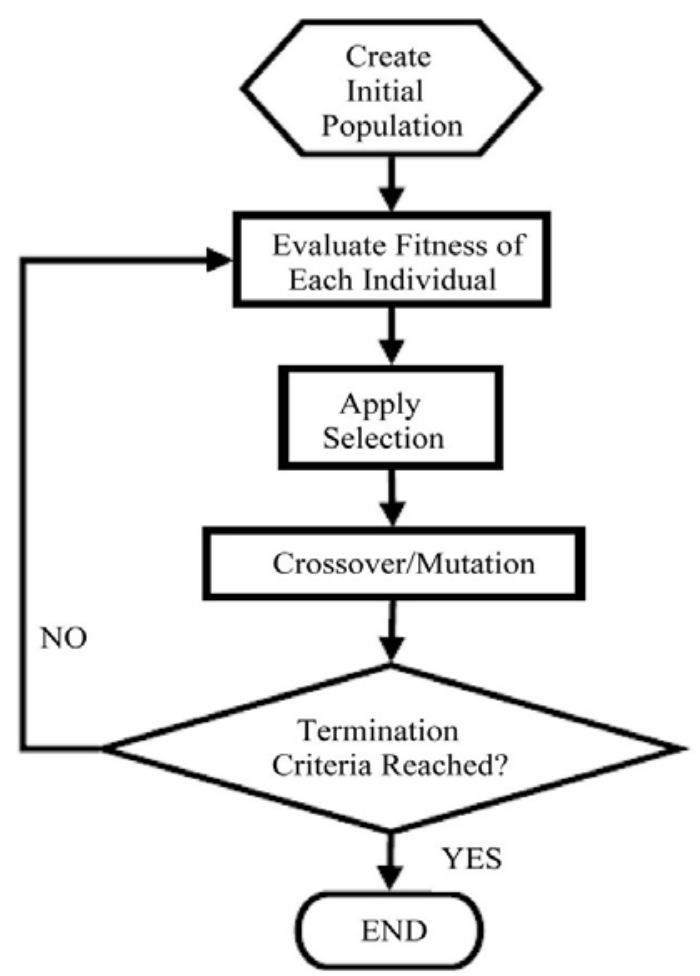

Figure 3. Genetic algorithm flowchart

Table 1. Power output of solar system at different times

\begin{tabular}{cccc}
\hline Time & $\mathbf{T}_{\text {morning }}$ & $\mathbf{T}_{\text {peak }}$ & $\mathbf{T}_{\text {evening }}$ \\
\hline Power & 2.2 & Expected value & 0.1 \\
\hline
\end{tabular}

\section{Mutation}

After completion of crossover of parentages, the process of mutation takes place in which a new generation is formed after randomly alteration of genes in order to establish different new traits. The genetic algorithm complete flow chart is shown in Figure 3.

\section{ELD MODELING WITH SOLAR POWER SYSTEM}

ELD model consisting of thermal power generating units and a solar power system is used to reduce the operating and fuel cost of the power system without affecting the running load. The power output of solar system at different times is given in Table 1.

Addition of Solar power system along with thermal generators in parallel to the power system increase the overall complexity of economic load dispatch problem (Liang and Glover, 1990; Khan et al., 2015; Nottrott et al., 2013). To cater these effects quadratic cost function of thermal generating units is used. Stochastic solar power, as a constaint in economic load dipatch model is represented as follows:

$$
\min _{x_{k}} y=\sum_{k=1}^{n} q_{k 0}+q_{k 1} x_{k}+q_{k 2} x_{k}^{2}
$$

subject to

$$
\begin{gathered}
S+\sum_{k=1}^{n} x_{k}=P_{d} \\
x_{\min , k} \leq x_{k} \leq x_{\max , k}, \forall i
\end{gathered}
$$

where

$q_{k 0}, q_{k 1}, q_{k 2} \quad$ Fuel cost coefficients.

$S \quad$ Solar power. 
European Journal of Sustainable Development Research, 2(3), 27

Table 2. System Parameters

\begin{tabular}{|c|c|c|c|}
\hline Generator Index k & $\mathrm{q}_{\mathrm{k} 2}$ & $\mathrm{q}_{\mathrm{k} 1}$ & $\mathrm{q}_{\mathrm{k} 0}$ \\
\hline 1 & 100 & 200 & 10 \\
\hline 2 & 120 & 150 & 10 \\
\hline 3 & 40 & 180 & 20 \\
\hline 4 & 60 & 100 & 10 \\
\hline 5 & 40 & 180 & 120 \\
\hline 6 & 100 & 150 & 10 \\
\hline
\end{tabular}

Table 3. Thermal generators limits

\begin{tabular}{ccc}
\hline No. of Gensets & Min Power & Max Power \\
\hline 1 & 0.021 & 0.51 \\
\hline 2 & 0.031 & 0.71 \\
\hline 3 & 0.051 & 1.21 \\
\hline 4 & 0.061 & 1.51 \\
\hline 5 & 0.051 & 1.31 \\
\hline 6 & 0.071 & 0.71 \\
\hline
\end{tabular}

Table 4. Solar plant technical parameters

\begin{tabular}{lll}
\hline Parameter & Specification & Quantity \\
\hline Type of Module & Solar Panels - PV Modules & \\
\hline Individual Power & Polycrystalline & 10,000 \\
\hline Array Global Power & Unit Norm Power & $250 \mathrm{~W}($ Peak $)$ \\
\hline No. of Solar PV Modules & Nominal Power at STC & $2500 \mathrm{KW}$ \\
\hline Array Operating Characteristics & In Series & 20 \\
\hline & In Parallel & 500 \\
\hline Number of Inverter & U mpp & $604 \mathrm{~V}$ \\
\cline { 2 - 3 } Total Power & \multicolumn{1}{c}{ Inverter } & $8.28 \mathrm{~A}$ \\
\hline
\end{tabular}

$x_{\min , k}, x_{\max , k} \quad$ Minimum and maximum genration limits of ith thermal generator.

$P_{d} \quad$ Load demand.

Output of Solar PV modules is varying in nature and is dependent on solar irradiation, temperature and several other factors such as soiling loses, dirt and wind velocity. Solar irradiance and ambient temperature are different at different intervals of a day and are a critical parameter for solar power production. In order to model the randomness of solar power, the probabilistic approach is used. Output of solar power is taken as a random variable (Gaing, 2013).

Due to different output of Solar PV plant at different intervals of a day, three intervals have been taken, at morning when solar output is minimum and is increasing, mid of the day when solar output power is maximum and in the evening when solar output is reducing. For this reason three expected values are used while solving economic load dispatch model. The output power of a PV plant can be obtained after solving equations of current and voltage (Yu and Rosehart, 2012).

$$
\begin{gathered}
I_{P V}=I_{P V}-I_{0} 1+\frac{n x}{1 !}+\frac{n(n-1) x^{2}}{2 !}+\cdots \\
I=I_{S c}-I_{0}\left\{\exp \left[\frac{q\left(V+I R_{s}\right)}{K T}\right]-1\right\}-\left(\frac{V+I R_{s}}{R_{p}}\right) \\
V=V_{d}-I R_{S}
\end{gathered}
$$

The power from Solar PV plant is taken at three intervals. Using the bionomial Theorem current of PV plant is calculated, and similarly the voltage is calculated by using the abov model.

\section{RESULTS AND DISCUSSION}

The system comprising of six thermal power generating units and a solar power system is taken under observation for this paper. With help of Matlab, ELD for the system under consideration is simulated. Table 2 shows the technical parameters and specifications of the six thermal power generators. Cost coefficient parameters of the thermal generators are denoted by $q_{i 2}, q_{i 1}$ and $q_{i 0}$. 
Table 5. Optimal solution of rated solar power $=2.2 \mathrm{pu}$

\begin{tabular}{cccc}
\hline & Minimum & Average & Maximum \\
\hline $\mathrm{x}_{1}$ & 0.2697 & 0.3928 & 0.3831 \\
\hline $\mathrm{x}_{2}$ & 0.2469 & 0.4739 & 0.6737 \\
\hline $\mathrm{x}_{3}$ & 0.7054 & 0.8428 & 1.1589 \\
\hline $\mathrm{x}_{4}$ & 1.0129 & 1.0965 & 1.4293 \\
\hline $\mathrm{x}_{5}$ & 0.6852 & 0.8908 & 1.1563 \\
\hline $\mathrm{x}_{6}$ & 0.3584 & 0.5962 & 0.6942 \\
\hline
\end{tabular}

Table 6. Optimal solution of rated solar power $=1 \mathrm{pu}$

\begin{tabular}{|c|c|c|c|}
\hline & Minimum & Average & Maximum \\
\hline $\mathrm{x}_{1}$ & 0.3136 & 0.3038 & 0.38310 \\
\hline $\mathrm{x}_{2}$ & 0.5145 & 0.4867 & 0.67371 \\
\hline $\mathrm{x}_{3}$ & 0.9427 & 1.007 & 1.15891 \\
\hline $\mathrm{x}_{4}$ & 1.2024 & 1.3915 & 1.4294 \\
\hline $\mathrm{x}_{5}$ & 1.0089 & 1.3 & 1.1563 \\
\hline $\mathrm{x}_{6}$ & 0.5155 & 0.5065 & 0.6942 \\
\hline
\end{tabular}

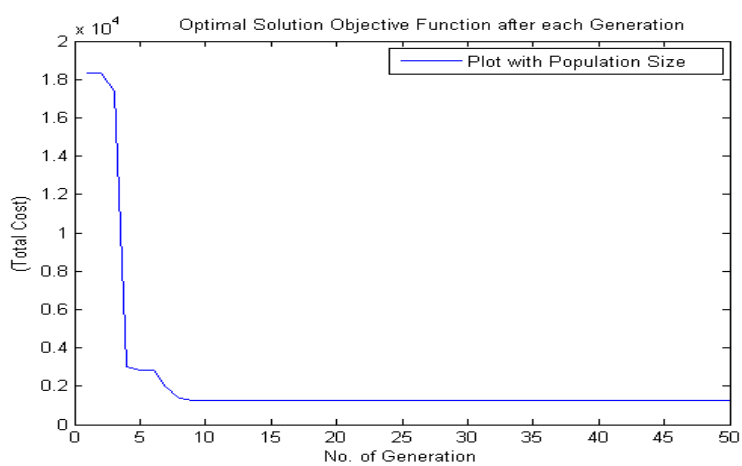

Figure 4. Case 1: Economic load dispatch convergence at zero solar power

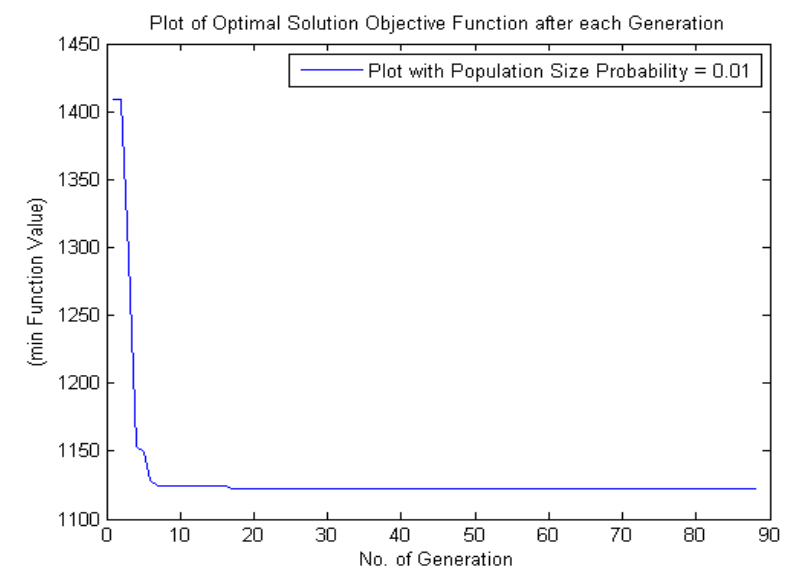

Figure 5. Case 2: Economic load dispatch convergence at average solar power

The base of test system is 100 MVA. Minimum and Maximum output power also known as Generation limit (Bakirtzis et al., 1994) defining the inequality constraints of each thermal generator is presented in Table 3 . The parameters of solar power plant are given in Table 4.

The different rated values of solar is considered, the value of rated power is 2.2 and $1 \mathrm{pu}$. It is assumed that the output of solar power plant is changed at different time interval. Output of thermal generating unit is changed depending upon the load demand and instantaneous production of solar power plant. We have taken total of fifty iterations for Genetic Algorithm. The crossover probability used is 0.9 and mutation probability used is 0.01 . For the stated issue, the ideal solution is given in Table 5 and 6 for rated solar plant 2.2 pu and 1 pu.

We have taken three cases for ELD problem. Case 1, when solar power is zero (evening time) and generation of thermal units is maximum. Case 2, when solar power is on average (at early morning and evening time) and generation of thermal units is according to the load. Case 3, when solar power is maximum (at sun peak hours), thermal generation is only to overcome the deficiency of solar power to properly run the load.

For all these three cases, at rated solar power of 1pu, are shown in Figures 4, 5 and 6 respectively. 


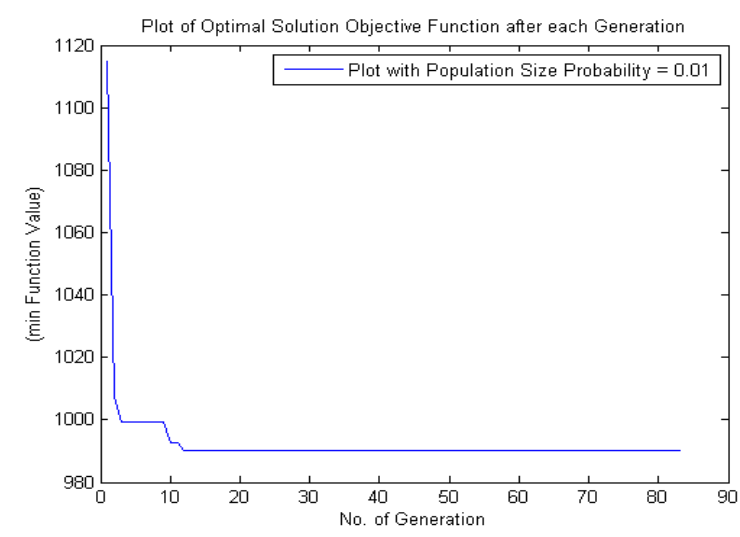

Figure 6. Case 3: Economic load dispatch convergence at maximum solar power

\section{REFERENCES}

Bakirtzis, A., Petridis, V. and Kazarlis, S. (1994). Genetic algorithm solution to the economic dispatch problem. Proc. IEE Trans. Gen., Trans. Distrib., 141(4), 377-382. https://doi.org/10.1049/ip-gtd:19941211

Gaing, Z. L. (2013). Particle swarm optimization to solving the economic dispatch considering the generator constraints. IEEE Trans. on Power Systems, 18, 1187-1195. https:// doi.org/10.1109/TPWRS.2003.814889

Khan, N., Awan, A. and Mahmood, A. (2015). Combined emission economic dispatch of power system including solar photo voltaic generation. Energy Conversion and Management, 92, 82-91. https://doi.org/10.1016/j.enconman.2014.12.029

Khan, F., Fahad, M. and Aziz, A. (2015). Genetic algorithm based optimization of economic load dispatch constrained by stochastic wind power. International Conference on Open Source Systems \& Technologies (ICOSST).

Liang, Z. X. and Glover, J. D. (1990). Improved Cost Functions for Economic Dispatch considerations. IEEE Transaction on Power Systems, 821-829.

Liu, X. (2010). Economic load dispatch constrained by wind power availability: a wait-and-see approach. IEEE trans. on smart grid, 1(3). https://doi.org/10.1109/TSG.2010.2057458

Nottrott, A., Kleissl, J. and Washom, B. (2013). Energy dispatch schedule optimization and cost benefit analysis for grid-connected, photovoltaic-battery storage systems. Renewable Energy, 55, 230-240. https://doi.org/10.1016/j.renene.2012.12.036

Phonrattanasak, P., Miyatake, M. and Sakamoto, O. (2013). Optimal location and sizing of solar farm on japan east power system using multiobjective bees algorithm. Energytech, 1-6. https://doi.org/10.1109/EnergyTech.2013.6645334

Safie, F. M. (1989). Probabilistic modeling of solar power systems. IEEE, Reliability and Maintainability Symposium Proceedings, Annual. https://doi.org/10.1109/ARMS.1989.49639

Shilaja, C. and Ravi, K. (2017). Optimization of emission/economic dispatch using euclidean affine flower pollination algorithm (eFPA) and binary FPA (BFPA) in solar photo voltaic generation. Renewable Energy, 107, 550-556. https://doi.org/10.1016/j.renene.2017.02.021

Yu, H. and Rosehart, W. D. (2012). An optimal power flow algorithm to achieve robust operation considering load and renewable generation uncertainties. Power Systems, IEEE Transactions on, 27(4), 1808-1817. https://doi.org/10.1109/TPWRS.2012.2194517 